\title{
The Role of Lipins in Innate Immunity and Inflammation
}

\author{
María A. Balboa*, Nagore de Pablo, Clara Meana, and Jesús Balsinde \\ Instituto de Biología y Genética Molecular, Consejo Superior de Investigaciones
}

Científicas (CSIC), 47003 Valladolid, Spain, and

Centro de Investigación Biomédica en Red de Diabetes y Enfermedades Metabólicas

Asociadas (CIBERDEM), 28029 Madrid, Spain

*To whom correspondence should be addressed: Instituto de Biología y Genética Molecular, Calle Sanz y Forés 3, 47010 Valladolid, Spain. Phone, 34-983-184-833; FAX, 34-983-184-800; E-mail: mbalboa@ibgm.uva.es

Key words: lipin, macrophages, inflammation, diacylglycerol, phosphatidic acid

Abreviations: ASC, apoptosis-associated speck-like protein with a CARD domain; $\mathrm{CPLA}_{2} \alpha$, cytosolic phospholipase $A_{2} \alpha$; DAG, diacylglycerol; DSS, dextran sodium sulfate; LD, lipid droplet; LDL, low-density lipoproteins; LPS, lipopolysaccharide; NLRP, nucleotide-binding domain, leucine-rich family, pyrin domain containing; PA, phosphatidic acid; PAP, phosphatidic acid phosphohydrolase/phosphatase; SFA, saturated fatty acids; TAG, triacylglycerols; TLR, Tol-like receptor; VLDL, very lowdensity lipoproteins 


\begin{abstract}
Lipins are phosphatidic acid phosphatase enzymes whose cellular function in regulating lipid metabolism has been known for decades, particularly in metabolically active tissues such as adipose tissue or liver. In recent years evidence is accumulating for key regulatory roles of the lipin family in innate immune cells. Lipins may help regulate signaling through relevant immune receptors such as Toll-like receptors, and are also integral part of the cellular machinery for lipid storage in these cells, thereby modulating certain inflammatory processes. Mutations in genes that encode for members of this family produce autoinflammatory hereditary diseases or diseases with an important inflammatory component in humans. In this review we summarize recent findings on the role of lipins in cells of the innate immune system and in the onset and progress of inflammatory processes.
\end{abstract}




\section{Introduction}

$\mathrm{Mg}^{2+}$-dependent phosphatidate phosphatases, formerly abbreviated as PAP-1 enzymes, now known as lipins, were the latest enzymes of the de novo lipid biosynthetic pathway to be described at a molecular level [1, 2]. The two lipids whose levels are regulated by lipins, namely phosphatidic acid (PA) and 1,2,-diacylglycerol (DAG), not only contribute to membrane biogenesis by participating in the biosynthesis of glycerophospholipids, but may also bind to and activate a number of signaling proteins, thereby inducing a vast array of cellular responses [2-4]. Finally, DAG may be acylated to form triacylglycerol (TAG), an energy storage lipid that accumulates in lipid droplets (LDs) [5-7].

The lipin family is encoded by three different genes (LPIN1, LPIN2 and LPIN3 in humans and Ipin1, Ipin2 and Ipin3 in mice). LPIN1/Ipin1 may undergo alternative splicing to produce lipin-1 $\alpha, 1 \beta$ or $1 \gamma$ in humans; in contrast, lipin- $1 \gamma$ has not been found in mice. The best characterized members of the family are lipin-1 and lipin-2, likely because mutations in their genes produce disease in humans or lead to striking phenotypic changes in mice $[1,8]$. All lipins (lipin-1, -2 and -3 ) share a similar structure with conserved domains at the $\mathrm{N}$ - and $\mathrm{C}$ - terminus of the molecule known as N-LIP and C-LIP, a nuclear localization sequence (NLS) close to the N-LIP, and catalytic (DxDxT) and transcriptional coactivator (LxxIL) motifs located within the C-LIP domain (Fig. 1). Because of the presence of the later motif, lipins, especially lipin-1, are believed to influence gene transcription events by coactivating metabolic transcription factors such as PPAR $\alpha$ or PPARy, or by directly interacting with inflammatory transcription factors such as NFATc4 to repress its activity [9-11]. All the lipins appear to bind to their substrate PA via hydrogen bond switch mechanisms promoted by the polybasic domain present in their nuclear localization sequence $[12,13]$. Much recent effort has been put into characterizing transcriptional and post-transcriptional events and protein-protein interactions that regulate the expression and activity of lipins in different cells and tissues. A complete description of these processes is beyond the scope of this article, and the interested reader is kindly referred to a number of recent excellent reviews on the subject [14-18]. 


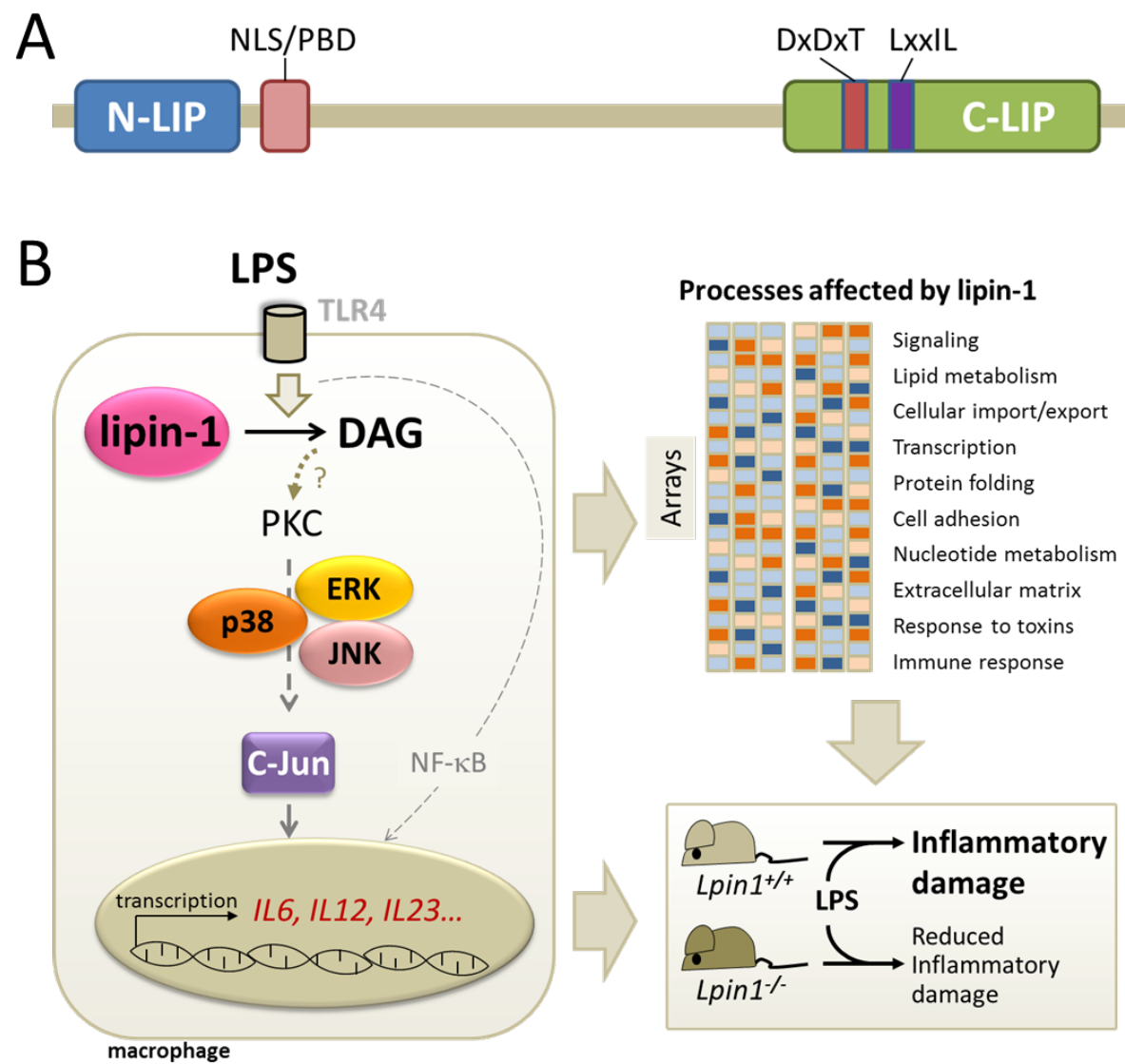

Figure 1. General protein structure of the lipin family, and involvement of lipin-1 in TLR4-signaling. A, Shown are the N-LIP and C-LIP conserved domains, and the polybasic domain (PBD) that serves as the nuclear localization signal (NLS) and the PA binding motif. The C-LIP domain contains the DxDxT catalytic motif and the LxxIL transcriptional co-activator motif. B, Lipin-1 participates in TLR4 signaling by affecting different biological processes and the development of systemic inflammation. For details see text.

Macrophages are cells of the innate immune system that possess the ability to recognize different molecular patterns present in pathogens and damaged cells, and mount the appropriate inflammatory response to eliminate them and repair the injured area. In addition to their protective functions, macrophages also participate in the pathogenesis of diseases such as atherosclerosis [19], colitis [20], tumorigenesis [21], autoinflammatory diseases [22], or metabolic diseases [23]. The capacity of macrophages to respond to harmful stimuli or mount pathological responses depends on many factors, being their metabolic status a striking one [24]. Macrophages express lipin-1, lipin-2 and lipin-3 [25]. These enzymes regulate the cellular levels of PA, DAG, phospholipids and TAG during activation by multiple stimuli; thus they play a major role in macrophage physiology and pathophysiology. In the following sections we describe in detail the recent advances on the regulation of macrophage-mediated reactions by lipins. 


\section{Lipin-1 impact on TLR4-mediated signaling}

TLR4 is a pattern recognition receptor used by innate immune cells to respond to bacterial lipopolysaccharide (LPS). Once LPS engages TLR4, the receptor initiates intricate signaling events that promote inflammatory gene expression to stop and eliminate the infection. Signaling starts when several adaptor proteins and kinases are recruited to TLR4, and culminates in the activation of the transcription factors NF-KB and AP-1 [26]. In LPS-stimulated bone marrow-derived macrophages, lipin-1 has been found to be required for the full phosphorylation of the MAPKs ERK, JNK and p38 [27] (Fig. 1). As a consequence, complete phosphorylation/activation of c-Jun, which is part of the transcription factor AP-1 and is phosphorylated by MAPKs, also needs lipin-1. Interestingly, a different branch of TLR4 signaling that ends in the activation of NF-KB, seems not to be influenced by the phosphatase. In fact, cells deficient in lipin-1 exhibit the same degradation levels of the NF-KB inhibitors IKB $\alpha$ and IKB $\beta$ as wild type cells [27]. Thus, lipin-1, far from impacting on all the signaling branches associated with TLR4, appears to be restricted to those events that involve MAPK activation. In studies with RAW264.7 macrophages treated with lentiviral short hairpin RNAs to silence lipin1 , no effect was found on LPS-induced p38 phosphorylation activation cascades [28]. This difference could be attributed to the different cell system used or to an incomplete reduction of lipin-1 levels in those cells.

From a lipid point of view, the two lipids directly related with lipin activity, PA and DAG, could affect MAPK activation by different mechanisms. PA is long known to bind directly to a specific polybasic site within the kinase domain of Raf-1 kinase, a MAP3K [2]. PA may also bind to Sos, a guanine nucleotide exchange factor for Ras, thus activating the Ras/Raf/ERK cascade [29]. More recently, KSR (kinase suppressor of Ras) a scaffold protein that may bind MEK-1 and ERK-1 and initiate kinase signaling, has also been described as a PA target [30]. In Schwann cells, lipin-1 has been shown to reduce the levels of PA, which leads to diminished phosphorylation of MAPKs [31]. In macrophages however, a similar scenario appears unikely because in these cells it is the absence of lipin-1 that leads to reduced MAPK phosphorylation [27]. Future experimentation taking advantage of lipidomics approaches to measure cellular PA levels should clarify this point.

Regarding DAG, it is well documented that this lipid binds/activates or changes the localization of many proteins implicated in signal transduction pathways [32]. Among them, the best characterized are probably the classical and novel members of the protein kinase $C$ family $[33,34]$, which may lie upstream of MAPKs during TLR4 activation [35]. Lipin-1 participates in the production of DAG during TLR4 engagement with LPS [27]. Thus the easiest assumption is that lipin-1-derived DAG could bind and assist in the activation of one or more protein kinase Cs and in this way participate in MAPKs phosphorylation [36]. 
As a consequence of its supporting role of TLR4-mediated signal transduction, lipin-1 influences the magnitude of production of many inflammatory factors in activated murine and human macrophages, thereby impacting in the progress of the inflammatory process [27] (Fig. 1). Experiments aimed at evaluating the systemic response of animals to LPS treatment, demonstrated that lipin-1 delays the recovery. Animals deficient in lipin-1 had a quicker recovery, likely due to the lower production of harmful proinflammatory cytokines in these animals [27] (Table I). In fact, these animals exhibited lower levels of damage markers such as urea, blood urea nitrogen, creatinine, alanine aminotransferase and aspartate aminotransferase [27].

Table I. Lipin KO models of disease

\begin{tabular}{|c|c|c|c|c|c|}
\hline Mice & Description & Disease model & Treatments & Outcome & Reference \\
\hline \multicolumn{6}{|l|}{ Lipin-1 } \\
\hline $\begin{array}{l}\text { Fatty liver } \\
\text { distrophy }(f l d)\end{array}$ & $\begin{array}{l}\text { Lipin-1 deficient } \\
\text { mice }\end{array}$ & $\begin{array}{l}\text { Systemic } \\
\text { inflammation } \\
\text { Colitis } \\
\text { Inflammation driven } \\
\text { tumorigenesis } \\
\text { Myopathy }\end{array}$ & $\begin{array}{l}\text { Intraperitoneal } \\
\text { LPS treatment } \\
\text { 3\% DSS } 5 \text { days } \\
\text { AOM+3\%DSS (3 } \\
\text { rounds) }\end{array}$ & $\begin{array}{l}\text { Lower inflammation } \\
\text { Lower colon } \\
\text { inflammation } \\
\text { Lower tumor } \\
\text { burden and tumor } \\
\text { size } \\
\text { Exacerbated muscle } \\
\text { damage }\end{array}$ & $\begin{array}{l}76 \\
76 \\
88\end{array}$ \\
\hline Lipin-1 ${ }^{\text {mEnzy }}$ KO & $\begin{array}{l}\text { Myeloid-specific } \\
\text { lipin-1-PAP activity } \\
\text { deficient mice }\end{array}$ & Atherosclerosis & $\begin{array}{l}\text { High fat, Western } \\
\text { diet, } 21 \% \text { fat by } \\
\text { weight (0.15\% } \\
\text { cholesterol) }\end{array}$ & $\begin{array}{l}\text { reduced } \\
\text { atherosclerotic } \\
\text { burden }\end{array}$ & 70 \\
\hline mLipin-1KO & $\begin{array}{l}\text { Myeloid-specific } \\
\text { lipin-1 deficient } \\
\text { mice }\end{array}$ & $\begin{array}{l}\text { Ethanol-Induced } \\
\text { Liver Injury }\end{array}$ & $\begin{array}{l}\text { Ethanol intake for } \\
10 \text { days }\end{array}$ & $\begin{array}{l}\text { Ameliorated } \\
\text { inflammation and } \\
\text { alcoholic hepatitis }\end{array}$ & 85 \\
\hline Lipin-1LKO & $\begin{array}{l}\text { Hepatocyte-specific } \\
\text { lipin-1-PAP activity } \\
\text { deficient mice }\end{array}$ & $\begin{array}{l}\text { Alcohol-induced } \\
\text { steatohepatitis }\end{array}$ & $\begin{array}{l}\text { Low-fat liquid diet } \\
\text { with ethanol for } 4 \\
\text { weeks }\end{array}$ & $\begin{array}{l}\text { Exacerbation of the } \\
\text { disease }\end{array}$ & 86 \\
\hline $\begin{array}{l}\text { MCK-Lpin1 } 1^{\Delta 115} \\
\text { and } \\
\text { MCK-Lpin1-/- } \\
\text { mice }\end{array}$ & $\begin{array}{l}\text { Muscle-specific } \\
\text { lipin-1 PAP activity } \\
\text { deficient mice and } \\
\text { muscle-specific } \\
\text { lipin-1 mice, } \\
\text { respectively }\end{array}$ & Myopathy & - & Muscle damage & 89 \\
\hline $\begin{array}{l}\text { HSA } \\
\text { 3/frex } /+/ / \text { Lpin } 1^{f E \times 2-}\end{array}$ & $\begin{array}{l}\text { Muscle-specific } \\
\text { lipin-1 deficiency }\end{array}$ & Myopathy & - & Muscle damage & 90 \\
\hline \multicolumn{6}{|l|}{ Lipin-2 } \\
\hline Lipin-2 KO & $\begin{array}{l}\text { Mice deficient in } \\
\text { lipin-2 }\end{array}$ & $\begin{array}{l}\text { Autoinflammatory } \\
\text { disorder (Majeed } \\
\text { Syndrome) }\end{array}$ & $\begin{array}{l}\text { Intraperitoneal } \\
\text { LPS treatment }\end{array}$ & $\begin{array}{l}\text { Exacerbated } \\
\text { production of IL-1 } \beta\end{array}$ & 103 \\
\hline
\end{tabular}

A non-biased broad analysis of gene expression further demonstrated that lipin-1 has a sizeable impact on different biological processes that drive macrophage behavior during TLR4 stimulation (Fig. 1). The enzyme not only influences the expression of genes related with signaling, i.e. cellular receptors, kinases/phosphatases, and G-protein-related genes, but also affects the expression of 
genes related to lipid metabolism, cellular import/export, transcription, protein folding modification, cell adhesion, nucleotide metabolism, extracellular matrix, response to toxins and immune response [27]. The number and nature of changes observed in gene expression that are due to the enzyme activity of lipin-1 versus those which are due to its transcriptional coactivator activity are yet to be described.

Lipin-1 may also influence macrophage activation through other TLR receptors in addition to TLR4. During stimulation with specific ligands for TLR3 (Poly I:C) or TLR1/2 (Pam3CSK4), full enhanced expression of inflammatory genes like $/ / 6$ or $/ 123 a$ requires the presence of lipin-1 [27]. Whether the signaling effectors affected by lipin1 are or not the same for all TLRs is unknown at present.

\section{Involvement of lipin-1 in cPLA $2 \alpha$ activation and eicosanoid production}

One of the hallmarks of macrophages responding to inflammatory stimuli is the activation of group IVA phospholipase $A_{2}$ (cytosolic phospholipase $A_{2} \alpha, c P L A_{2} \alpha$ ) [3739]. Phospholipase $A_{2}$ enzymes cleave the fatty acid present at the $s n-2$ position of the glycerol backbone of phospholipids. CPLA $2 \alpha$ is in this regard particularly important, because it manifests selectivity for glycerophospholipids containing arachidonic acid at the $s n-2$ position, and availability of this fatty acid in free form is a limiting step for the biosynthesis of eicosanoids [37-39], molecules widely involved in both the initiation and resolution of inflammation [40]. Full activation of $\mathrm{CPLA}_{2} \alpha$ depends on its phosphorylation status and the increase of cytosolic $\mathrm{Ca}^{2+}$ concentrations that allow enzyme translocation to membranes where its substrate is localized [41-45]. Lipins, as enzymes implicated in the production of DAG, may impact on CPLA $2 \alpha$ activation in several ways. It is known that DAG is capable of increasing the activity of the enzyme, perhaps by separating the polar headgroups of phospholipids in membranes, thus allowing a better accessibility of the enzyme to its substrate. Also, DAG can initiate phosphorylation signaling cascades culminating in the activation of MAPKs, which phosphorylates $\mathrm{CPLA}_{2} \alpha$ and helps to maintain the enzyme in its active form [37-39] (Fig. 2).

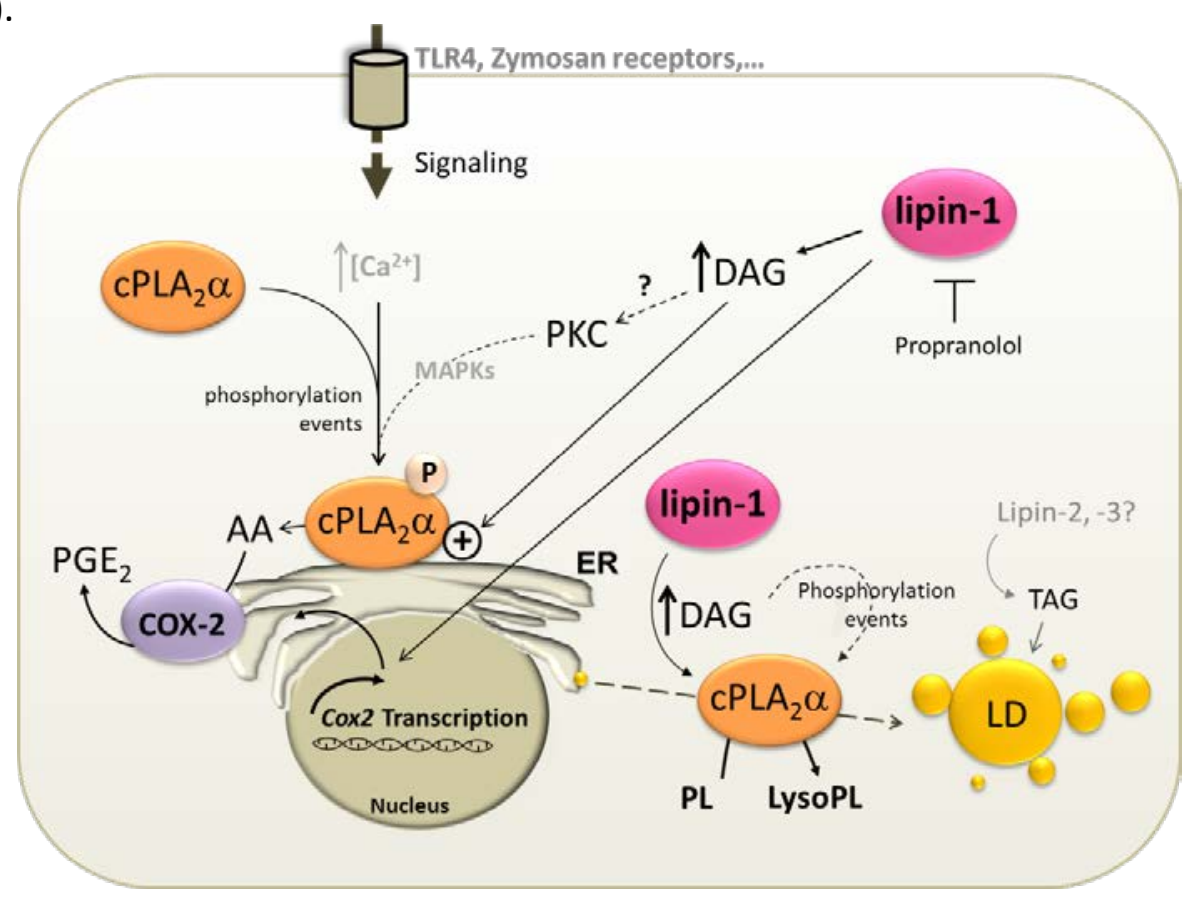


Figure 2. Lipin-1 participates in eicosanoid production and regulates LD biogenesis in macrophages. During macrophage activation through TLRs or zymosan receptors, DAG generated by lipin-1 participates in AA release by influencing $\mathrm{CPLA}_{2} \alpha$ phosphorylation, probably through PKC enzymes and membrane substrate accessibility. Lipin-1 also helps in the transcriptional upregulation of the enzyme COX-2. Lipin-1 controls LD biogenesis by regulating CPLA $2 \alpha$ activity and phosphorylation but it does not seem to participate in TAG synthesis.

Studies with non-phagocytic cells carried out in the 90's, where PAP-1 activity was inhibited by propranolol, provided the first indication for its involvement in $\mathrm{CPLA}_{2} \alpha$ regulation [36]. A subsequent study with RAW264.7 macrophages, showing the involvement of PAP-1 activity in AA release secondary to TLR4 engagement, confirmed that a link between PAP-1 and CPLA $2 \alpha$ also exists in innate immune cells [46]. The same study highlighted the importance of lipin-1-derived DAG for these responses, since treatment of macrophages with a cell-permeable DAG, i.e. 1,2-dioctanoylglycerol, restored the capacity of cells with a reduced PAP-1 activity to release AA during activation [46]. Moreover, evidence was also presented for the involvement of protein kinase $C$ in $C P L A_{2} \alpha$ activation, albeit a direct link between PAP-1 and protein kinase $C$ via DAG formation was not shown [46] (Fig. 2). Future experimentation in this area should aim to characterize the specific PKC isofoms that are activated by the DAG species generated by lipin-1 during conditions leading to CPLA $2 \alpha$ activation.

Due to its ability to impact on signaling events initiated by kinases, DAG may influence nuclear transduction events. For example, activation of protein kinase $C$ often results in the activation of the transcription factor AP-1, which has many sequence targets in inflammation-related genes, e.g. Cox2 [47]. The product of this gene, COX-2, is the enzyme responsible for initiating the sequence of AA oxidation reactions ending in prostaglandin synthesis. Interestingly, Grkovich et al. [48] described that PAP-1 activity may also be necessary for full COX-2 expression and PGE 2 production in human 4937 macrophage-like cells stimulated through TLR4 [48]. Altogether, these studies suggested that PAP-1 activity contributes to the generation of eicosanoids by regulating two different events, namely the activation of $\mathrm{CPLA}_{2} \alpha$ to release AA from phospholipids, and the upregulation of COX-2 expression to metabolize the fatty acid $[46,48]$. More recent studies in human monocyte-derived macrophages where lipin-1 was silenced using siRNA technology demonstrated that AA release, $\mathrm{CPLA}_{2} \alpha$ phosphorylation and $\mathrm{PGE}_{2}$ production were all dependent on cellular lipin-1 expression [49]. In the same way, macrophages from animals deficient in lipin-1 were found to express lower levels of Cox 2 mRNA and COX-2 protein during TLR4 activation than macrophages expressing the phosphatase [27]. These observations support the idea that lipin-1 contributes to the generation of eicosanoids. It is currently unknown whether other members of the lipin family also participate in this process. 
Other eicosanoid-producing enzymes such as 5-lipoxygenase have also been suggested to lie downstream PAP-1 activity in innate immune cells. Experiments conducted with human polymorphonuclear leukocytes showed that propranolol inhibits the nuclear translocation of 5-lipoxygenase, and subsequent leukotriene synthesis [50]. The effect of propranolol was prevented when cells were treated with 1,2-dioctanoylglycerol, suggesting the involvement of PAP-1 activity [50]. Further work will be needed to define the specific lipin form involved.

\section{Lipin-1 and lipid droplets}

Lipid droplets (LD) are cytoplasmic organelles for the storage of neutral lipids such as TAG and cholesterol esters. Extensive recent research has demonstrated that in addition to acting as cellular energy storage depots, LDs are highly dynamic organelles with multiple functions, maintaining physical contact with other cellular organelles and helping to coordinate cellular metabolism [51]. Also, they serve a detoxifying role in cells by protecting them from the deleterious effects of high concentrations of saturated free fatty acids, by storing the excess fatty acid into TAG $[25,52]$. In immune cells, LDs were also defined as platforms for eicosanoid production [53-55]. Interestingly, $\mathrm{CPLA}_{2} \alpha$ has been found to translocate to this organelle [56], and its enzyme activity and phosphorylation status appear to constitute essential factors for LD biogenesis [57-60]. However, the mechanism may not involve mobilizing AA or regulating the synthesis of neutral lipids, but rather facilitating the budding of nascent LDs from the endoplasmic reticulum [5] (Fig. 2).

In human and murine macrophages, lipin-1 regulates the size and number of LDs per cell, an effect that is particularly noteworthy in cells exhibiting a foam likestate due to treatment with oleic acid to promote LD biogenesis [49]. However, at least in human macrophages, the role of lipin-1 in LD formation may not be related with the biosynthesis of TAG, because the incorporation of free fatty acids such as oleic acid into TAG, does not change when the enzyme is absent [49]. This striking observation was later corroborated in mature 3T3-L1 adipocytes [61]. Perhaps other lipins (-2 or -3) participate directly in the synthesis of TAG under these conditions. In this regard, lipin2 has been implicated in TAG synthesis in macrophage cell lines during palmitic acid overload [25]. Future experimentation will be needed to clarify this important issue.

A pathophysiological scenario where LD biogenesis and enlargement is very relevant for macrophages is during the onset of atherosclerosis. Macrophages present in the intima of arteries engulf enormous amounts of modified LDLs which are processed, and their cholesterol content is stored as cholesterol esters in LDs, contributing to foam cell development. While not being involved in the uptake of 
acetylated or oxidized LDLs by macrophages, lipin-1 has recently been found to regulate LD formation in macrophages exposed to these modified LDLs [28].

\section{Role of lipin-1 during pathogenic bacterial infection}

During infection of macrophages with pathogenic bacteria, the microorganisms may take over lipid synthesis pathways from the host to evade inflammatory responses generated to eliminate them. Some of these microorganisms appear to use lipins to accomplish these actions. A good example is Francisella tularensis, a highly infectious Gram-negative bacterial pathogen that escapes macrophage phagolysosomes to avoid destruction [62], producing tularemia [63]. The initial finding that $F$. tularensis attenuates host inflammatory responses in humans was described in the early 60's and corroborated later in mice $[64,65]$. One of the proposed mechanisms for immune evasion of the pathogen is the synthesis of the eicosanoid prostaglandin $E_{2}$ [66]. Treatment of lung-infected mice with indomethacin, a drug that inhibits prostaglandin $E_{2}$ production, decreases bacterial burden. Furthermore, indomethacin increases the numbers of IFN $\gamma^{+}$T cells in the lungs of infected animals. IFN $\gamma$ is key for host clearance of $F$. tularensis [66-68].

In vitro, macrophages infected with $F$. tularensis upregulate COX-2 expression and produce prostaglandin $E_{2}$ in a lipin-1-dependent manner [68]. Lipin-1, however, does not seem to be related with the growth of the bacteria inside the macrophages. Therefore, it has been postulated that host lipin-1 is important in vivo to generate the appropriate environment for the pathogen to survive and grow and, as mentioned before for other models, it would act as a signaling molecule to induce the synthesis of prostaglandin $E_{2}[67,68]$. Future experimentation using lipin-1-deficient animals, and/or animals with specific lipin-1 deletion in macrophages, should be utilized to characterize this scenario further.

Another good example of how pathogens manipulate lipid synthesis pathways to thrive in their hosts, is the aerobic gram-negative intracellular pathogen Legionella pneumophila. It produces Legionnaire's disease, a severe type of pneumonia in humans. In this case, bacteria engulfed by professional phagocytes reside within a unique phagosome (the Legionella-containing vacuole, LCV) that the pathogen adapts for survival, changing, among other things, its lipid composition [69]. Studies performed in yeast have described that the bacteria manipulates the levels of the lipid biosynthetic precursor PA using two effectors, Lpda and LecE. LpdA has phospholipase $D$ activity that makes PA from phosphatidylcholine, while LecE activates, via an unknown mechanism, the yeast PAP (Pah1), producing DAG from PA. Altering in this way the lipid composition of its environment, L. pneumophila recruits other bacterial effectors and host cell proteins to the LCV to improve bacterial survival and replication 
conditions [69]. Importantly, LpdA and LecE are also present inside the phagosome where the bacteria reside during infection of human macrophages [69]. It has not been described yet whether LecE also influences the activation status of lipins in human macrophages.

\section{Lipin-1 and atherosclerosis}

Atherosclerosis is an inflammatory disease of the artery that underlies the origin of cardiovascular disease. Accumulation of oxidized low-density lipoproteins (LDLs) and attraction and activation of macrophages play a key role in atherosclerotic plaque formation. Lipin-1 is present in human atherosclerotic plaques and colocalizes with CD68, a marker of macrophages [28]. In animal models, mice fed a proatherogenic diet show higher levels of lipin-1 in their aortic arch than mice fed a regular diet. These data and the findings that lipin-1 has a proinflammatory role in macrophages and modulates lipid accumulation under certain circumstances [25, 27] encouraged Navratil et al. to evaluate the role of lipin-1 in these cells under proatherogenic conditions [28]. They found that lipin-1 is required for the accumulation of lipids in macrophages (foam cells) upon treatment with modified LDLs (oxidized or acetylated) in vitro, an effect that could be due to the regulation of de novo lipid synthesis for lipid droplet generation. In accord with this, treatment with oxidized LDLs did not increase DAG levels in the absence of lipin-1. Importantly under these settings, lipin-1 seemed to be the link between the accumulation of lipids and the increased production of proinflammatory factors. In fact, in the absence of lipin-1, proinflammatory cytokines were very much reduced [28]. The mechanism by which lipin-1, and specifically its PAP-1 activity, is involved in the induction of inflammation in macrophages treated with modified LDLs may involve a persistent activation of the signaling cascade PKC $\alpha / \beta$ II-ERK-C-Jun (Fig. 3A) [70]. This behavior seems to be specific for the activation of macrophages with modified LDLs, since other stimuli like LPS do not generate long term activation of the PKC $\alpha / \beta$ II-ERK-c-Jun cascade $[70,27]$.

In an effort to unambiguously address the role of lipin-1 activity in myeloid cells during atherosclerosis development, Woolard and associates developed a murine model where the enzyme activity of lipin-1 was specifically absent from the myeloid linage [70] (Table I). In vitro analysis of bone-marrow-derived macrophages from these animals demonstrated that lipin-1 activity participates in the accumulation of DAG and neutral lipid during treatment with oxidized LDLs. The effect takes place without altering the uptake of oxidized LDL, as judged by determination of the cellular content in cholesterol esters [70]. It has to be stressed at this point that foamy macrophages are able to internalize oxidized LDLs by other receptors different from LDLR, for example scavenger receptors like CD36, and that their expression seems not to be controlled by the enzyme activity of lipin-1 [70]. 


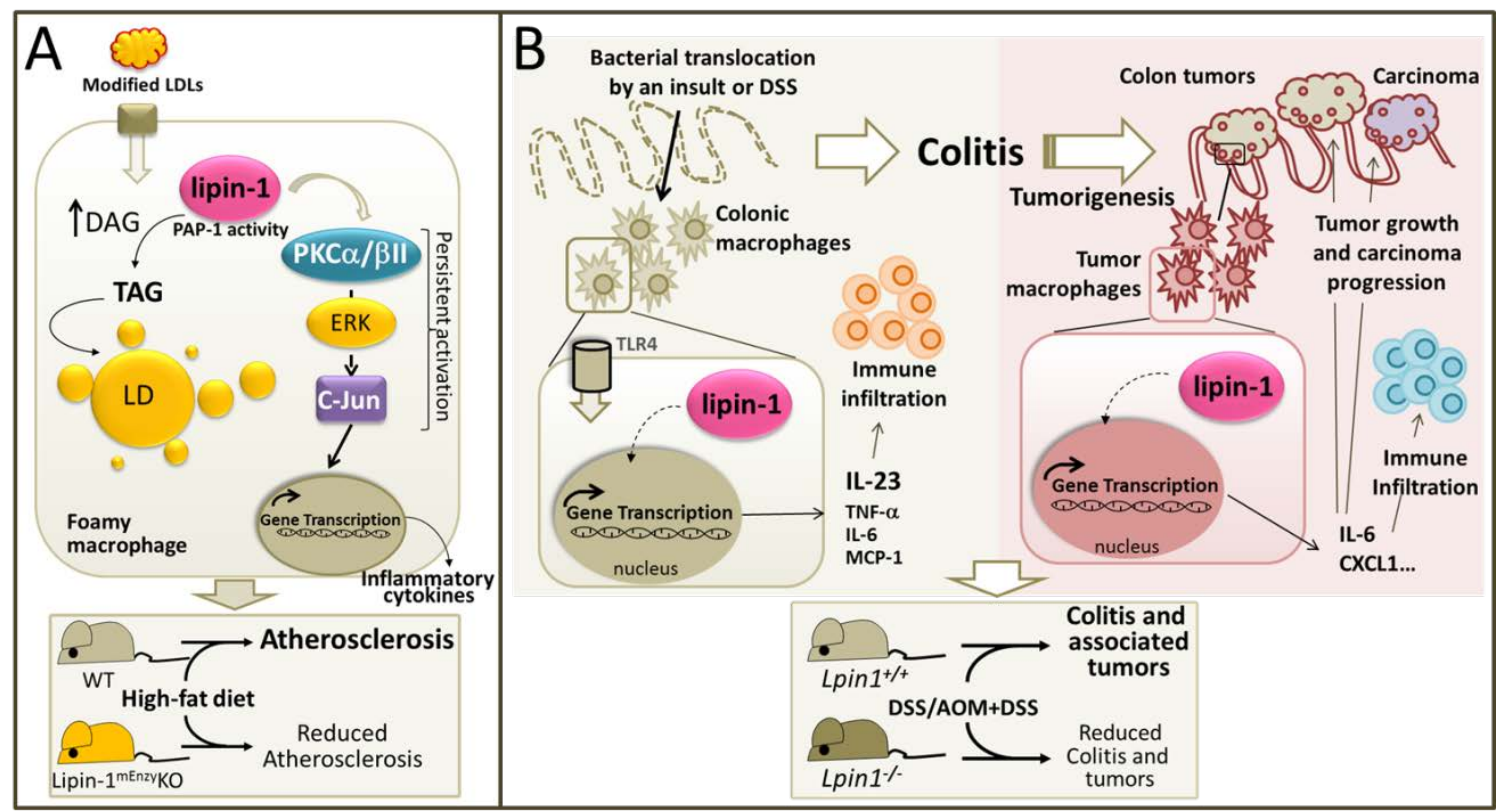

Figure 3. Lipin-1 participates in atherosclerosis, colitis and colitis-associated tumor development. A, Lipin-1 enzyme activity is involved in TAG biosynthesis, persistent activation of PKC $\alpha / \beta I / / E R K / C-J u n$, inflammatory cytokine production and foam cell development during tretament with modified LDL. In the absence of myeloid cell lipin-1 enzyme activity, atherosclerosis development is reduced. B, Lipin-1 participates in proinflammatory activation of colon macrophages during colitis development, influencing immune infiltration and disease severity. During colitis-based tumorigenesis lipin-1 is expressed in tumor-associated macrophages, producing IL-6 and CXCL1 that aid immune infiltration, tumor growth and carcinoma progression events.

Atherosclerosis was then induced in the aforementioned model by overexpressing a gain-of-function mutation (D377Y) of the mouse proprotein convertase subtilisin/kexin type 9, which reduces the levels of hepatic LDL receptors; and by a high-fat diet, to generate hypercholesterolemia [70, 71] (Table I). The results showed that, in myeloid cells, the enzyme activity of lipin-1 is important for atherosclerosis development of (Fig. 3A). Lipin-1 activity positively affected plaque number and size in the aortas of the animals. The effect was observed even when plasma cholesterol levels in animals with or without lipin-1 activity in myeloid cells were similar. It is also important to note here that the enzyme seems not to control the cellular composition of the plaque, suggesting that monocyte recruitment to the artery wall does not involve the activity of lipin-1 during plaque development. Circulating TNF- $\alpha$ levels in animals fed a high-fat diet were found to be lower in animals deficient in myeloid lipin-1 activity than in wild type animals [70]. Overall, these studies elegantly demonstrate that the enzyme activity of lipin-1 plays a fundamental role in the myeloid lineage when atherosclerosis develops, and confirm the role of the enzyme in inflammatory processes arising from disregulated lipid overload. Future work should investigate the particular species of DAG synthesized by lipin-1 that promote PKC activation in this system, and also whether lipin-1 and/or its 
activity is also relevant for other cellular types involved in atherosclerosis, such as endothelial cells or smooth muscle cells.

\section{Lipin-1 in colitis and colitis-associated cancer}

One of the proinflammatory factors whose expression is most affected by lipin-1 during LPS treatment of macrophages is IL-23 [25]. This cytokine is produced by dendritic cells and macrophages in the intestine and its expression is enhanced during colitis development in animal models as well as in patients with Crohn's disease or ulcerative colitis [72-74]. Blockade of IL-23 with antibodies reduces inflammation during experimental colitis [75]. In an animal model of dextran sodium sulfate (DSS)induced colitis, lipin-1 was found to influence disease severity by driving the proinflammatory activation state of innate immune cells such as macrophages, and the production of IL-23 in the colon [76] (Table I). Lipin-1 promotes animals to experience greater weight losses during treatment with DSS, increases the number of mucosal ulcers, architectural distortion, regenerative changes and the length of the affected colon. Lipin-1 also aids in the production of inflammatory factors other than IL-23, i.e. IL-6, TNF- $\alpha$ or IL-1 $\beta$, and increases the inflammatory infiltration in the colon, with higher numbers of innate immune cells and $\mathrm{CD} 4^{+} \mathrm{T}$ cells. As anticipated from previous studies performed in vitro [27], isolated colonic macrophages display enhanced proinflammatory activation when expressing lipin-1. Further, because at least half of the enzyme activity of these macrophages arises from lipin-1, it seems reasonable to assume that the enzyme activity of lipin-1 is important for the proinflammatory activation of these cells [76]. The relevance of lipin-1 in macrophages during colitis development was experimentally demonstrated by adoptive transfer of lipin-1expresing macrophages into animals deficient in the enzyme [76]. Also, treatment of lipin-1-deficient animals with IL-23, was sufficient to increase disease severity, confirming the importance of IL-23 in this model [76] (Fig. 3B). Whether IL-23 produced by other cells different from macrophages also contributes to disease severity in a lipin-1-dependent manner or whether lipin-1 could be important for colitis development in other cells besides macrophages are still open questions.

When colitis becomes chronic, tumors may develop. Inflammatory bowel diseases are among the major factors contributing to colon cancer in humans [77]. Due to the role of lipin-1 in colitis development, Meana et al. [76] studied the possible implication of the phosphatase in colitis-associated tumorigenesis (Fig. 3B) (Table I). In their study, animals were treated with the mutagen azoxymethane, followed by three rounds of treatment with DSS. This leads to the appearance of measurable tumors after 80 days of commencing the treatment. Animals deficient in lipin-1 had less and smaller tumors than wild type animals [76]. The effects can be explained on the basis of the negative influence that lipin-1 has over apoptotic events that favor the 
expression of the antiapoptotic proteins $\mathrm{Bcl} 2$, while helping proliferative events, as demonstrated by the higher expression of the proliferation marker Ki67 in the colon of animals with tumors that express lipin-1 [76].

Importantly, lipin-1 was also key for tumor progression to carcinomas. In fact, very few in situ carcinomas and no invasive carcinomas were detected in animals deficient in lipin-1. Lipin-1 participates in the production of factors that are very relevant to promote the growth of tumor epithelial cells like IL-11, IL-6 or iNOS, and also on the production of factors that mediate dysplasia-carcinoma transition events like CXCL1 and CXCL2 [76, 78, 79], explaining its involvement in the above mentioned processes. In human colon tumors there exists a very high correlation between the expression levels of LPIN1 and the expression levels of CXCL1, CXCL2, IL6, IL11, IL23A and PTGHS2/COX2 [76]. These data further support the pro-inflammatory and protumorigenic role of lipin-1 in this scenario [76].

In cancers and tumor cells from non-colonic tissue, such as prostate cancers, triple negative breast cancer and lung cancer, lipin-1 expression appears to be important for tumor cell survival and tumor progression [80-82]. Lipin-1 expression is increased in all of the aforementioned types of human cancer. Actually, for triple negative breast cancer, lung cancer and some types of colon cancer, the expression level of lipin-1 defines survival rates or relapse-free survival rates of patients [76, 80, 82]. Lipin-1 has intrinsic roles in human epithelial tumor cells and increases proliferation/survival events in cells from prostate, lung and triple negative breast tumors [80-82]. It is not known at this time whether the same applies to cells from human colon tumors. However, immunohistochemistry analyses in mice reveal that lipin-1 is not expressed in the colonic tumor compartment, being its expression confined to the stromal compartment [76]. There, lipin-1 is mainly expressed by macrophages, which affects not only the activation state of those cells, but also their infiltration into the tumors [76]. Future data from colon cancers of patients should define whether the same occurs in humans. Overall, these data indicate that the cellular niche where lipin-1 exerts its pro-tumorigenic actions seems to be dependent on the origin of the tumor.

\section{Relevance of lipin-1 expression in myeloid cells to inflammation development during alcoholic liver steatosis}

Alcoholic liver disease is caused by heavy and chronic alcohol consumption and is the most prevalent chronic liver disease worldwide. It starts with a reversible accumulation of fat in the liver, but if alcohol consumption continues, fibrosis, cirrhosis and hepatocarcinoma may develop, accounting for a sizeable number of deaths every year [83]. The disease develops with liver inflammation and damage for reasons that are 
still not fully known. Ethanol increases liver expression of lipin-1, whose PAP-1 activity participates in the accumulation of TAG that takes place in this context [84].

You and colleagues documented in two separate studies the role of lipin-1 in hepatocytes and cells of the myeloid lineage in response to ethanol $[85,86]$ (Table I). Although the two studies are not totally comparable due to differences in the background of the mice utilized and the type of diet provided to the animals, the data suggest that the role of lipin-1, regarding liver inflammation and damage, varies substantially depending on the cell type $[85,86]$. Specific elimination of lipin-1 in hepatocytes positively impacts on liver inflammation and damage generated by ethanol intake [86]. However, specific elimination of lipin-1 in myeloid cells ameliorates the development of inflammation and liver damage generated by ethanol [85]. Interestingly, the absence of lipin-1 in either of the two cellular compartments increased lipid accumulation in the liver during ethanol intake [86, 85], raising questions as to whether those lipids actually participate in inflammation and damage development, what is their molecular identity and which cellular compartment they are affecting.

In liver, the absence of lipin-1 in myeloid cells of ethanol-fed mice reduces the expression of the neutrophil marker Ly6G, the levels of myeloperoxidase activity, and the activation of the proinflammatory nuclear transcription factor NF-kB [85]. Along their study, the authors found increased expression of adiponectin in adipose tissue and fibroblast growth factor (FGF) 15 in gut [85]. Both hormones possess antiinflammatory effects and, intriguingly, one seems to regulate the expression of the other and vice versa [85]. Future work should reveal how adiponectin and FGF15 actually affect proinflammatory signaling in the liver and how the elimination of lipin-1 in myeloid cells impacts on it.

\section{Lipin-1 and rhabdomyolysis}

Mutations in LPIN1 generate myopathies in humans, which are a frequent genetic cause of rhabdomyolysis in children [87]. This is a serious condition where the destruction of the skeletal muscle liberates creatine kinase, electrolytes, and myoglobin to the blood stream. If untreated, acute kidney injury may develop that is associated with high morbidity and mortality. Episodes of rhabdomyolysis are precipitated by crush injuries, certain medications like statins or anesthetics and, interestingly, febrile illnesses, some of which are associated to viral or bacterial infections [87].

Three recent papers have shed some light into the mechanisms by which the absence of lipin-1 promotes myopathy [88-90]. By using different murine models to study disease development, some of them with specific elimination of lipin-1 or its 
enzyme activity in the muscle (Table I), these works demonstrated that myopathy is produced specifically by the absence of lipin-1 PAP activity in skeletal muscle [88-90]. These findings recapitulate previous observations showing that lipin-1 accounts for the majority of PAP-1 activity in skeletal muscle [88-90].

Myopathy due to deficiency in lipin-1 or its PAP activity appears to be associated with a reduced autophagic flux, which leads to accumulation of damaged mitochondria, and also with a severe ER stress in skeletal muscle [88-90]. Because of the high muscle damage produced by the absence of lipin-1 or its PAP activity, inflammation ensues $[89,90]$. Mononuclear cell infiltration has been described in the muscle of lipin-1-deficient animals, with increased expression of macrophage markers. These cells likely arrive to the muscle to eliminate injured myocytes and repair the area, and their presence increases with myopathy progression and age [89]. Proinflammatory gene expression also increases in those muscles, especially Tnfa, II6 and $/ / 1 b$ [89]. Why infections initiate the episodes of the disease, and how the immune system counteracts, or helps, are still open questions.

\section{Lipin-2 controls proinflammatory signaling triggered by saturated fatty acids.}

Saturated fatty acids (SFA) are released at high amounts from stressed adipose tissue under conditions where elevated quantities of lipids exist, for example obesity. SFA have proinflammatory effects in macrophages by directly activating surface receptors, promoting ER stress or changing cellular metabolism [91-93]. Since much of the deleterious effects of SFA is due to the high concentrations they can reach in the intracellular milieu, a good counteracting measure would be to diminish their levels by channeling them to the formation of TAG. Given that lipins are central enzymes in the de novo TAG synthesis pathway, studies were conducted to assess the role of the lipin family of proteins in SFA-induced activation of human and murine macrophages [25]. Using siRNAs to specifically silence Lpin1, Lpin2 or Lpin3, it was found that only depletion of lipin-2 reduced the production of proinflammatory cytokines such as IL-6, MCP-1 ( $C c / 2)$ and TNF- $\alpha$ by macrophages exposed to high palmitic acid concentrations [25]. Lipin-2 was found to restrict JNK phosphorylation and, subsequently, the phosphorylation and activation of the AP-1 transcription factor protein c-Jun [25]. Specific inhibitors of JNK (SP600125) or Jnk1 or c-Jun silencing also decreased the overproduction of the aforementioned inflammatory cytokines in the same manner as that achieved by lipin-2 silencing. Thus, lipin-2 channels excessive levels of intracellular palmitic acid to TAG formation and, in this way ameliorates the proinflammatory activation induced by the fatty acid.

\section{Lipin-2 control of NLRP3 inflammasome activation: lessons from Majeed syndrome}


Mutations in the gene coding for lipin-2 in humans (LPIN2) produce a hereditary, autosomal recessive, and rare disease called Majeed syndrome, named after the investigator who first described it $[8,94]$. Clinically, the symptoms are: recurrent fever, chronic recurrent multifocal osteomyelitis, dyserythropoietic anemia and, sometimes, psoriasis. The disease may start a few weeks after birth [88]. It was classified as an autoinflammatory disease because its symptoms are reduced with therapy against IL$1 \beta$ or its receptor, but not against TNF- $\alpha$, a feature that characterizes autoimmune diseases [95]. Majeed syndrome is a special type of autoinflammatory disease because it is not due to mutations in genes related with the inflammasome, the intracellular multiprotein machinery that produces the maturation of pro-IL1 $\beta$ to its mature form IL-1ß [8].

Inflammasomes are assembled in innate immune cells to generate responses against pathogens and, in fact, they may recognize multiple molecular patterns present in microorganisms. The final mission of inflammasomes is the activation of caspase-1, a protease that cleaves pro-IL-1 $\beta$. There are several true inflammasomes, named after the molecule that serves as the receptor of the complex, mainly NLRP1 (nucleotide-binding domain, leucine-rich family, pyrin domain containing 1), NLRP3, NLRP4c, NLRP6, pyrin and AIM2 (absent in melanoma 2) [96]. Of them, the best characterized and also the one capable of recognizing a wider number of molecular patterns and danger signals, is the NLRP3 inflammasome [97]. After recognition of its ligand, it undergoes a conformational change that allows binding of an adaptor protein called ASC (apoptosis-associated speck-like protein with a CARD domain), common to several inflammasomes. Pro-caspase-1 is then attached to the complex NLRP3-ASC, undergoing a self-cleavage that releases active caspase-1 peptides [98] (Fig. 4). One of the proposed cellular events that NLRP3 senses is a drop of intracellular $\mathrm{K}^{+}$levels [99, 100].

Experimentally, canonical activation of the NLRP3 inflammasome is achieved by priming of the immune cell through TLR ligands or other receptors, like the TNF- $\alpha$ receptor, to transcriptionally upregulate the expression of pro-IL-1 $\beta$. Afterward, a second signal is needed to activate the assembly of the inflammasome per se. This is achieved by the activation of other types of membrane receptors, such as the $\mathrm{P}_{2} \mathrm{X}_{7}$ receptor by high ATP doses. The receptor then opens a pore that allows entry of cations such as $\mathrm{Ca}^{2+}$ or $\mathrm{Na}^{+}$, and the exit of $\mathrm{K}^{+}$. As a whole, extracellular ATP is recognized by the cell as a danger signal, the NLRP3 is then assembled, probably after the drop of intracellular $\mathrm{K}^{+}$levels, caspase- 1 is activated and pro-IL-1 $\beta$ is converted to mature IL-1 $\beta$ [101-102] (Fig. 4). 


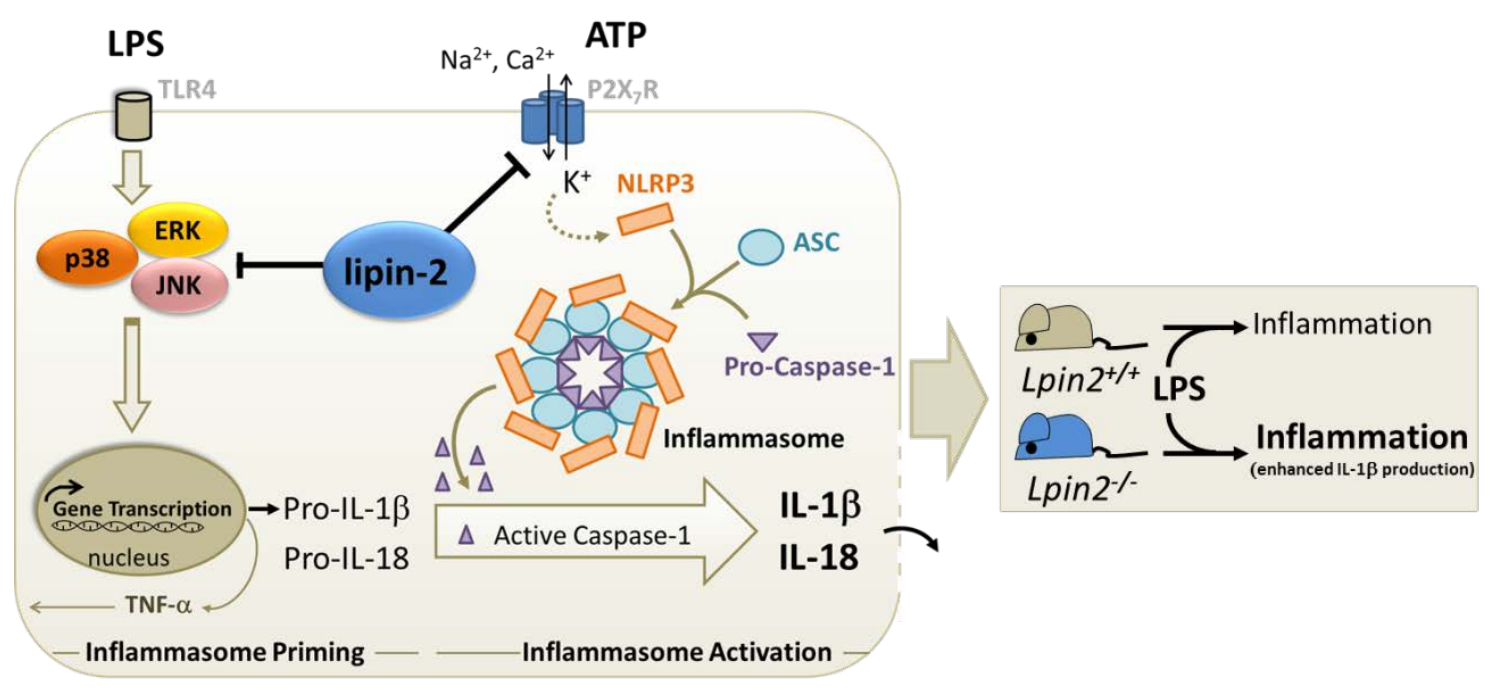

Figure 4. Lipin-2 controls inflammasome activation. Lipin-2 prevents full TLR4 signaling during the priming phase of inflammasome activation, and $P 2 X_{7} R$ pore opening during the inflammasome activation phase, thus reducing maturation of IL-1 $\beta$ and IL-18. Animals deficient in lipin-2 show reduced levels of IL-1 $\beta$ when treated with LPS.

Based on previous findings on the role of lipin-2 in controlling inflammation by saturated fatty acids and the correlation between the Majeed Syndrome and IL-1 $\beta$ production, Lordén et al. went on to study the possible mechanism by which the enzyme could regulate an excessive synthesis of IL-1 $\beta[25,103]$. The findings showed that lipin- 2 controls IL-1 $\beta$ overproduction by influencing the priming as well as the activation phase of the NLRP3 inflammasome activation, both in human and murine macrophages [103].

Regarding the priming step, and contrary to lipin-1, lipin-2 restricts TLR4 signaling in macrophages [103]. Macrophages deficient in lipin-2 which are treated with LPS generate more TNF- $\alpha$ and pro-IL-1 $\beta$ than control cells. This effect depends on the regulatory actions that lipin-2 exerts on MAPK phosphorylation, particularly those leading to p38 and JNK activation [103]. Activated p38 behaves as a key step for $1 / 1 b$ transcriptional up-regulation in macrophages $[103,104]$, while JNK seems to be necessary for phosphorylation processes occurring during the inflammasome activation phase [103, 105]. Importantly, during LPS priming, lipin-2 limits the induction of NLRP3, which exerts a stark influence on the cell's capacity to assemble the NLRP3 inflammasome afterward [103] (Fig. 4).

Analysis of IL-18 production, a cytokine that is also proteolytically matured by the inflammasome, but whose immature form is already expressed in non-activated cells [106], demonstrated that lipin-2 has the capacity to regulate the second phase of inflammasome activation as well [103]. The effect is achieved by blunting the intracellular drop in $\mathrm{K}^{+}$, inflammasome assembly, and caspase-1 activation, which reduces IL-1 $\beta$ maturation and pyroptosis, a type of cell death initiated by the inflammasome [103]. 
Opening of the $\mathrm{P}_{2} \mathrm{X}_{7}$ pore by ATP stimulation appears to be regulated by cellular cholesterol levels, which is due to the presence of certain sequences in the $\mathrm{N}$ terminal and proximal $C$-terminal parts of the receptor that generate multiple cholesterol recognition amino acid consensus motifs [107]. It has been described that lowering cholesterol levels by cellular treatment with methyl- $\beta$-cyclodextrin, increases the amplitude of the $\mathrm{P} 2 \mathrm{X}_{7}$ pore and, as a consequence, the cationic currents generated during the activation of the receptor by ATP [107]. Interestingly, when the levels of cholesterol were measured in cells deficient in lipin-2, they were found significantly decreased [103]. Treatment of lipin-2-deficient cells with exogenous cholesterol reestablished the amplitude and opening time of the pore generated by $\mathrm{P} 2 \mathrm{X}_{7}$ receptor activation, thus decreasing $\mathrm{K}^{+}$exit of the cell. Thus, lipin- 2 helps to maintain cellular membrane cholesterol levels which restrict ionic currents generated after ATP activation of the $\mathrm{P} 2 \mathrm{X}_{7}$ receptor, inhibiting the drop of intracellular $\mathrm{K}^{+}$levels that activates the assembly of the inflammasome [103]. How lipin-2 affects cellular cholesterol content is still an open question (Fig. 4).

In mice, activation of the inflammasome by an intraperitoneal injection of LPS is also negatively regulated by lipin-2. In fact, lipin-2-deficient animals exhibit higher levels of IL-1 $\beta$ and TNF- $\alpha$ in serum, thus manifesting both enhanced inflammasome activation and enhanced TLR4 activation [103] (Fig. 4).

Collectively, the above mentioned findings helped to categorize Majeed syndrome as a NLRP3 inflammasomopathy [108], reinforcing the use of therapy against IL-1 $\beta$ or its receptor, and opening new treatment options for patients in the future. For example, the use of inhibitors against NLRP3, p38, JNK or $\mathrm{P}_{2} \mathrm{X}_{7}$ receptor could be evaluated as potentially beneficial for the control of IL-1 $\beta$ in subjects with mutations in lipin-2.

\section{Conclusions}

Lipins have been described as important modulators of inflammatory responses orchestrated by cells of the innate system such as macrophages. This is due to the enormous need of these cells to continuously generate membrane, to their lipid storage capacity and also to the intricate signaling processes of their surface receptors involving lipid networks. Macrophages express lipin-1, -2 and -3 , but to date, only lipin1 and -2 have been studied in detail. Interestingly, lipin-1 plays proinflammatory functions while lipin-2 plays anti-inflammatory functions. These effects appear to depend on the antagonistic regulation that they exert on receptors such as the TLRs, on the different roles that they play during LD biogenesis and TAG synthesis, and on the unique role for lipin-2 to control inflammasome assembly. Lipin-1 participates in the development of inflammatory diseases such as atherosclerosis, colitis and colitis- 
drived carcinogenesis, and also in metabolic diseases with an inflammatory component like rhabdomyolisis or alcoholic liver disease. Lipin-2 expression, on the other hand, prevents the outcome of autoinflammatory disorders such as the Majeed syndrome. Future work in this rapidly moving field should shed new light into the possibility that lipins may also play significant roles in other innate immune cells in addition to macrophages, and should dissect new functions of the lipin family in physiology and pathophysiology. Possible therapeutic opportunities for inflammation-related diseases based in the knowledge currently available on lipins are encouraged.

\section{Acknowledgements}

Work in our laboratories was supported by the Spanish Ministry of Economy, Industry and Competitiveness (grants SAF2013-48201-R, SAF2015-73000-EXP and SAF201680883-R) (to J.B. and M.A.B.), and the Regional Government of Castile and Leon (BIO/VA03/14, BIO/VA22/15) (to M.A.B.). CIBERDEM is an initiative of Instituto de Salud Carlos III. NdP was supported by a predoctoral fellowship from the Spanish Ministry of Education and Culture (FPU Program).

\section{References}

[1] M. Péterfy, J. Phan, P. Xu, K. Reue, Lipodystrophy in the fld mouse results from mutation of a new gene encoding a nuclear protein, lipin, Nat. Genet. 27 (2001) 121124.

[2] G.-S. Han, W.-I. Wu, G. M. Carman, The Saccharomyces cerevisiae Lipin homolog is a $\mathrm{Mg}^{2+}$-dependent phosphatidate phosphatase enzyme. J. Biol. Chem. 281 (2006) 9210-9218.

[3] S. Ghosh, J.C Strum, V.A. Sciorra, L. Daniel, R.M. Bell, Raf-1 kinase possesses distinct binding domains for phosphatidylserine and phosphatidic acid. Phosphatidic acid regulates the translocation of Raf-1 in 12-0-tetradecanoylphorbol-13-acetatestimulated Madin-Darby canine kidney cells, J. Biol. Chem. 271 (1996) 8472-8480.

[4] Y. Nishizuka, Intracellular signaling by hydrolysis of phospholipids and activation of protein kinase C, Science 258 (1992) 607-614.

[5] C. Guijas, J. P. Rodríguez, J. M. Rubio, M.A. Balboa, J. Balsinde, Phospholipase $A_{2}$ regulation of lipid droplet formation, Biochim. Biophys. Acta 1841 (2014) 1661-1671.

[6] G.F. Wilgram, E.P. Kennedy, Intracellular distribution of some enzymes catalyzing reactions in the biosynthesis of complex lipids, J. Biol. Chem. 238 (1963) 2615-2619. 
[7] H. Wang, M.V. Airola, K. Reue, How lipid droplets "TAG" along: Glycerolipid synthetic enzymes and lipid storage, Biochim. Biophys. Acta Mol. Cell. Biol. Lipids. 1862 (2017) 1131-1145.

[8] P.J. Ferguson, S. Chen, M.K. Tayeh, L. Ochoa, S.M. Leal, A. Pelet, A. Munnich, S. Lyonnet, H.A. Majeed, H. El-Shanti, Homozygous mutations in LPIN2 are responsible for the syndrome of chronic recurrent multifocal osteomyelitis and congenital dyserythropoietic anaemia (Majeed syndrome), J. Med. Genet. 42 (2005) 551-557.

[9] B.N. Finck, M.C. Gropler, Z. Chen, T.C Leone., M.A. Croce, T.E. Harris, J.C. Jr. Lawrence, D.P. Kelly, Lipin 1 is an inducible amplifier of the hepatic PGC1alpha/PPARalpha regulatory pathway, Cell Metab. 4 (2006) 199-210.

[10] Y. K. Koh, M.Y. Lee, J.W. Kim, M. Kim, J.S. Moon, Y.J. Lee, Y.H. Ahn, K.S. Kim, Lipin1 is a key factor for the maturation and maintenance of adipocytes in the regulatory network with CCAAT/enhancer-binding protein alpha and peroxisome proliferatoractivated receptor gamma 2, J. Biol. Chem. 283 (2008) 34896-34906.

[11] H.B. Kim, A. Kumar, L. Wang, G.H. Liu, S.R. Keller, J.C. Jr. Lawrence, B.N. Finck, T.E. Harris, Lipin 1 represses NFATc4 transcriptional activity in adipocytes to inhibit secretion of inflammatory factors, Mol. Cell. Biol. 30 (2010) 3126-3139.

[12] J.M. Eaton, G.R. Mullins, D.N. Brindley, T.E. Harris, Phosphorylation of lipin 1 and charge on the phosphatidic acid head group control its phosphatidic acid phosphatase activity and membrane association, J. Biol. Chem. 288 (2013) 9933-9945.

[13] J.M. Eaton, S. Takkellapati, R.T. Lawrence, K.E. McQueeney, S. Boroda, G.R. Mullins, S.G. Sherwood, B.N. Finck, J. Villén, T.E. Harris, Lipin 2 binds phosphatidic acid by the electrostatic hydrogen bond switch mechanism independent of phosphorylation, J. Biol. Chem. 289 (2014) 18055-18066.

[14] B.P. Kok, G. Venkatraman, D. Capatos, D.N. Brindley, Unlike two peas in a pod: lipid phosphate phosphatases and phosphatidate phosphatases. Chem. Rev. 112 (2012) 5121-5146.

[15] X. Tang, M.G. Benesch, D.N. Brindley, Lipid phosphate phosphatases and their roles in mammalian physiology and pathology, J. Lipid. Res. 56 (2015) 2048-2060.

[16] S. Siniossoglou, Phospholipid metabolism and nuclear function: roles of the lipin family of phosphatidic acid phosphatases, Biochim. Biophys. Acta 1831 (2013) 575581.

[17] P. Zhang, K. Reue, Lipin proteins and glycerolipid metabolism: Roles at the ER membrane and beyond. Biochim. Biophys. Acta Biomembr. 1859 (2017) 1583-1595.

[18] M. You, A. Jogasuria, K. Lee, J. Wu, Y. Zhang, Y.K. Lee, P. Sadana, Signal Transduction Mechanisms of Alcoholic Fatty Liver Disease: Emer ging Role of Lipin-1, Curr. Mol. Pharmacol. 10 (2017) 226-236.

[19] G.J. Koelwyn, E.M. Corr, E. Erbay, K.J. Moore, Regulation of macrophage immunometabolism in atherosclerosis, Nat. Immunol. 19 (2018) 526-537. 
[20] S.T. Gren, O. Grip, Role of monocytes and intestinal macrophages in Crohn's disease and ulcerative colitis, Inflamm. Bowel Dis. 22 (2016) 1992-1998.

[21] A. Mantovani, F. Marchesi, A. Malesci, L. Laghi, P. Allavena, Tumour-associated macrophages as treatment targets in oncology, Nat. Rev. Clin. Oncol. 14 (2017) 399416.

[22] L. Agostini, F. Martinon, K. Burns, M.F. McDermott, P.N. Hawkins, J. Tschopp, NALP3 forms an IL-1beta-processing inflammasome with increased activity in MuckleWells autoinflammatory disorder, Immunity 20 (2004) 319-325.

[23] S.P. Weisberg, D. McCann, M. Desai, M. Rosenbaum, R.L. Leibel, A.W. Ferrante, Obesity is associated with macrophage accumulation in adipose tissue, J. Clin. Invest. 112 (2003) 1796-1808.

[24] L.A. O'Neill, R.J. Kishton, J. Rathmell, A guide to immunometabolism for immunologists, Nat. Rev. Immunol. 16 (2016) 553-565.

[25] M. Valdearcos, E. Esquinas, C. Meana, L. Peña, L. Gil-de-Gómez, J. Balsinde, M.A. Balboa, Lipin-2 reduces proinflammatory signaling induced by saturated fatty acids in macrophages, J. Biol. Chem. 287 (2012) 10894-10904.

[26] Y.C. Lu, W.C. Yeh, P.S. Ohashi, LPS/TLR4 signal transduction pathway, Cytokine 42 (2008) 145-151.

[27] C. Meana, L. Peña, G. Lordén, E. Esquinas, C. Guijas, M. Valdearcos, J. Balsinde, M.A. Balboa, Lipin-1 integrates lipid synthesis with proinflammatory responses during TLR activation in macrophages, J. Immunol. 193 (2014) 4614-4622.

[28] A.R. Navratil, A.E. Vozenilek, J.A. Cardelli, J.M. Green, M.J. Thomas, M.G. SorciThomas, A.W. Orr, M.D. Woolard, Lipin-1 contributes to modified low-density lipoprotein-elicited macrophage pro-inflammatory responses, Atherosclerosis 242 (2015) 424-432.

[29] C. Zhao, G. Du, K. Skowronek, M.A. Frohman, D. Bar-Sagi, Phospholipase D2generated phosphatidic acid couples EGFR stimulation to Ras activation by Sos, Nat. Cell Biol. 9 (2007) 706-712.

[30] C.A. Kraft, J.L. Garrido, E. Fluharty, L. Leiva-Vega, G. Romero, Role of Phosphatidic Acid in the Coupling of the ERK Cascade, J. Biol. Chem. 283 (2008) 36636-36645.

[31] K. Nadra, A.S. de Preux Charles, J.J. Médard, W.T. Hendriks, G.S. Han, S. Grès, G.M. Carman, J.S. Saulnier-Blache, M.H. Verheijen, R. Chrast, Phosphatidic acid mediates demyelination in Lpin1 mutant mice, Genes Dev. 22 (2008) 1647-1661.

[32] T.O. Eichmann, A. Lass, DAG tales: the multiple faces of diacylglycerolstereochemistry, metabolism, and signaling, Cell. Mol. Life Sci. 72 (2015) 3931-3952.

[33] Y. Takai, A. Kishimoto, U. Kikkawa, T. Mori, Y. Nishizuka, Unsaturated diacylglycerol as a possible messenger for the activation of calcium-activated, 
phospholipid-dependent protein kinase system, Biochem. Biophys. Res. Commun. 91 (1979) 1218-1224.

[34] A.C. Newton, Protein kinase C: perfectly balanced, Crit. Rev. Biochem. Mol. Biol. 53 (2018) 208-230.

[35] D.J. Loegering, M.R. Lennartz, Protein kinase C and toll-like receptor signaling, Enzyme Res. 2011 (2011) 537821.

[36] M.A. Balboa, J. Balsinde, E.A. Dennis, Involvement of phosphatidate phosphohydrolase in arachidonic acid mobilization in human amnionic WISH cells, J. Biol. Chem. 273 (1998) 7684-7690.

[37] A.M. Astudillo, M.A. Balboa, J. Balsinde, Selectivity of phospholipid hydrolysis by phospholipase $A_{2}$ enzymes in activated cells leading to polyunsaturated fatty acid mobilization, Biochim. Biophys. Acta 1864 (2019) 772-783.

[38] G. Pérez-Chacón, A.M. Astudillo, D. Balgoma, M.A. Balboa, J. Balsinde, Control of free arachidonic acid levels by phospholipases $A_{2}$ and lysophospholipid acyltransferases, Biochim. Biophys. Acta. 1791 (2009) 1103-1113.

[39] A.M. Astudillo, D. Balgoma, M.A. Balboa, J Balsinde, Dynamics of arachidonic acid mobilization by inflammatory cells, Biochim. Biophys. Acta. 1821 (2012) 249-256.

[40] E.A. Dennis, P.C. Norris, Eicosanoid storm in infection and inflammation. Nat. Rev. Immunol., 15 (2015) 511-523.

[41] J. Balsinde, M.V. Winstead, E.A. Dennis, Phospholipase $A_{2}$ regulation of arachidonic acid mobilization, FEBS Lett. 531 (2002) 2-6.

[42] J. Casas, M.A. Gijón, A. G. Vigo, M.S. Crespo, J. Balsinde, M.A. Balboa, Phosphatidylinositol 4,5-bisphosphate anchors cytosolic group IVA phospholipase $A_{2}$ to perinuclear membranes and decreases its calcium requirement for translocation in live cells, Mol. Biol. Cell 17 (2006) 155-162.

[43] J. Pindado, J. Balsinde, M.A. Balboa, TLR3-dependent induction of nitric oxide synthase in RAW 264.7 macrophage-like cells via a cytosolic phospholipase $\mathrm{A}_{2}$ /cyclooxygenase-2 pathway, J. Immunol. 179 (2007) 4821-4828.

[44] J. Casas, C. Meana, E. Esquinas, M. Valdearcos, J. Pindado, J. Balsinde, M.A. Balboa, Requirement of JNK-mediated phosphorylation for translocation of group IVA phospholipase $A_{2}$ to phagosomes in human macrophages, J. Immunol. 183 (2009) 2767-2774.

[45] V. Ruipérez, A.M. Astudillo, M.A. Balboa, J. Balsinde, Coordinate regulation of TLRmediated arachidonic acid mobilization in macrophages by group IVA and group $\mathrm{V}$ phospholipase $A_{2}$ S, J. Immunol. 182 (2009) 3877-3883.

[46] A. Grkovich, A. Armando, O. Quehenberger, E.A. Dennis, TLR-4 mediated group IVA phospholipase $A_{2}$ activation is phosphatidic acid phosphohydrolase 1 and protein kinase C dependent, Biochim. Biophys. Acta. 1791 (2009) 975-982. 
[47] Y.J. Kang, B.A. Wingerd, T. Arakawa, W.L. Smith. Cyclooxygenase-2 gene transcription in a macrophage model of inflammation. J. Immunol. 177 (2006) 81118122.

[48] A. Grkovich, C.A. Johnson, M.W. Buczynski, E.A. Dennis, Lipopolysaccharideinduced cyclooxygenase-2 expression in human 4937 macrophages is phosphatidic acid phosphohydrolase-1-dependent, J. Biol. Chem. 281 (2006) 32978-32987.

[49] M. Valdearcos, E. Esquinas, C. Meana, L. Gil-de-Gómez, C. Guijas, J. Balsinde, M.A. Balboa, Subcellular localization and role of lipin-1 in human macrophages, J. Immunol. 186 (2011) 6004-6013.

[50] D. Albert, C. Pergola, A. Koeberle, G. Dodt, D. Steinhilber, O. Werz, The role of diacylglyceride generation by phospholipase $D$ and phosphatidic acid phosphatase in the activation of 5-lipoxygenase in polymorphonuclear leukocytes, J. Leukoc. Biol. 83 (2008) 1019-1027.

[51] R. A. Coleman, M. K. Hesselink, Recent advances in lipid droplet biology, Biochim. Biophys. Acta 1862 (2017) 1129-1130.

[52] J.A. Olzmann, P. Carvalho, Dynamics and functions of lipid droplets, Nat. Rev. Mol. Cell. Biol. (2018).

[53] P.T. Bozza, I. Bakker-Abreu, R.A. Navarro-Xavier, C. Bandeira-Melo, Lipid body function in eicosanoid synthesis: an update, Prostaglandins Leukot. Essent. Fatty Acids. 85 (2011) 205-213.

[54] C.M. Maya-Monteiro, P.E. Almeida, H. D'Avila, A.S. Martins, A.P. Rezende, H. Castro-Faria-Neto, P.T. Bozza, Leptin induces macrophage lipid body formation by a phosphatidylinositol 3-kinase- and mammalian target of rapamycin-dependent mechanism, J. Biol. Chem. 283 (2008) 2203-2210.

[55] J.W. Meadows, B. Pitzer, D.E. Brockman, L. Myatt, Expression and localization of adipophilin and perilipin in human fetal membranes: association with lipid bodies and enzymes involved in prostaglandin synthesis, Clin. Endocrinol. Metab. 90 (2005) 23442350.

[56] R.E. Wooten, M.C. Willingham, L.W. Daniel, C.C. Leslie, L.C. Rogers, S. Sergeant, J. T. O'Flaherty, Novel translocation responses of cytosolic phospholipase $A_{2} \alpha$ fluorescent proteins. Biochim. Biophys. Acta 1783 (2008) 1544-1550.

[57] A. Gubern, J. Casas, M. Barceló-Torns, D. Barneda, X. de la Rosa, R. Masgrau, F. Picatoste, J. Balsinde, M.A. Balboa, E. Claro, Group IVA phospholipase $A_{2}$ is necessary for the biogenesis of lipid droplets, J. Biol. Chem. 283 (2008) 27369-27382

[58] A. Gubern, M. Barceló-Torns, D. Barneda, J.M. López, R. Masgrau, F. Picatoste, C.E. Chalfant, J. Balsinde, M.A. Balboa, E. Claro, JNK and ceramide kinase govern the biogenesis of lipid droplets through activation of group IVA phospholipase $A_{2}$, J Biol Chem, 284 (2009) 32359-32369. 
[59] A. Gubern, M. Barceló-Torns, D. Barneda, J.M. López, R. Masgrau, F. Picatoste, C.E. Chalfant, J. Balsinde, M.A. Balboa, E. Claro, JNK and ceramide kinase govern the biogenesis of lipid droplets through activation of group IVA phospholipase $A_{2}$, J. Biol. Chem. 284 (2009) 32359-32369.

[60] C. Guijas, G. Pérez-Chacón, A.M. Astudillo, J.M. Rubio, L. Gil-de-Gómez, M.A. Balboa, J. Balsinde, Simultaneous activation of p38 and JNK by arachidonic acid stimulates the cytosolic phospholipase $A_{2}$-dependent synthesis of lipid droplets in human monocytes, J. Lipid Res. 53 (2012) 2343-2354.

[61] H. Sembongi, M. Miranda, G.S. Han, S. Fakas, N. Grimsey, J. Vendrell, G.M. Carman, S. Siniossoglou, Distinct roles of the phosphatidate phosphatases lipin 1 and 2 during adipogenesis and lipid droplet biogenesis in 3T3-L1 cells, J. Biol. Chem. 288 (2013) 34502-34513.

[62] D.L. Clemens, B.Y. Lee, M.A. Horwitz, Virulent and avirulent strains of Francisella tularensis prevent acidification and maturation of their phagosomes and escape into the cytoplasm in human macrophages, Infect. Immun. 72 (2004) 3204-3217.

[63] A. Sjöstedt, Tularemia: history, epidemiology, pathogen physiology, and clinical manifestations, Ann. N. Y. Acad. Sci. 1105 (2007) 1-29.

[64] S.E. Greisman, R.B. Hornick, F.A. Jr. Carozza, T.E. Woodward, The role of endotoxin during typhoid fever and tularemia in man. I. Acquisition of tolerance to endotoxin, J. Clin. Invest. 42 (1963) 1064-1075.

[65] M. Telepnev, I. Golovliov, T. Grundström, A. Tärnvik, A. Sjöstedt, Francisella tularensis inhibits Toll-like receptor-mediated activation of intracellular signalling and secretion of TNF-alpha and IL-1 from murine macrophages, Cell. Microbiol. 5 (2003) 41-51.

[66] M.D. Woolard, J.E. Wilson, L.L. Hensley, L.A. Jania, T.H. Kawula, J.R. Drake, J.A. Frelinger, Francisella tularensis-infected macrophages release prostaglandin $E_{2}$ that blocks T cell proliferation and promotes a Th2-like response, J. Immunol. 178 (2007) 2065-2074.

[67] M.D. Woolard, L.L. Hensley, T.H. Kawula, J.A. Frelinger, Respiratory Francisella tularensis live vaccine strain infection induces Th17 cells and prostaglandin $E_{2}$, which inhibits generation of gamma interferon-positive T cells, Infect. Immun. 76 (2008) 2651-2659.

[68] A.R. Navratil, A.M. Brummett, J.D. Bryan, M.D. Woolard, Francisella tularensis LVS induction of prostaglandin biosynthesis by infected macrophages requires specific host phospholipases and lipid phosphatases, Infect. Immun. 82 (2014) 3299-3311.

[69] R. Viner, D. Chetrit, M. Ehrlich, G. Segal, Identification of two Legionella pneumophia effectors that manipulate host phospholipids biosynthesis, PLoS Pathog. 8 (2012) e1002988.

[70] A.E. Vozenilek, A.R. Navratil, J.M. Green, D.T. Coleman, C.M.R. Blackburn, A.C. Finney, B.H. Pearson, R. Chrast, B.N. Finck, R.L. Klein, A.W. Orr, M.D. Woolard, 
Macrophage-associated lipin-1 enzymatic activity contributes to modified low-density lipoprotein-induced proinflammatory signaling and atherosclerosis, Arterioscler. Thromb. Vasc. Biol. 38 (2018) 324-334.

[71] M.M. Bjørklund, A.K. Hollensen, M.K. Hagensen, F. Dagnaes-Hansen, C. Christoffersen, J.G. Mikkelsen, J.F. Bentzon, Induction of atherosclerosis in mice and hamsters without germline genetic engineering, Circ. Res. 114 (2014) 1684-1689.

[72] P.P. Ahern, C. Schiering, S. Buonocore, M.J. McGeachy, D.J. Cua, K.J. Maloy, F. Powrie, Interleukin-23 drives intestinal inflammation through direct activity on T cells, Immunity 33 (2010) 279-288.

[73] S. Hue, P. Ahern, S. Buonocore, M.C. Kullberg, D.J. Cua, B.S. McKenzie, F. Powrie, K.J. Maloy, Interleukin-23 drives innate and T cell-mediated intestinal inflammation, J. Exp. Med. 203 (2006) 2473-2483.

[74] A.R. Moschen, H. Tilg, T. Raine, IL-12, IL-23 and IL-17 in IBD: immunobiology and therapeutic targeting, Nat. Rev. Gastroenterol. Hepatol. (2018).

[75] R. Wang, S.Z. Hasnain, H. Tong, I. Das, A. Che-Hao Chen, I. Oancea, M. Proctor, T.H. Florin, R.D. Eri, M.A. McGuckin, Neutralizing IL-23 is superior to blocking IL-17 in suppressing intestinal inflammation in a spontaneous murine colitis model, Inflamm. Bowel. Dis. 21 (2015) 973-984.

[76] C. Meana, G.G. Rostán, L. Peña, G. Lordén, A. Cubero, A. Orduña, B. Györffy, J. Balsinde, M.A. Balboa, The phosphatidic acid phosphatase lipin-1 facilitates inflammation-driven colon carcinogenesis, JCl Insight 3 (2018): e97506.

[77] L. Beaugerie, S.H. Itzkowitz, Cancers complicating inflammatory bowel disease, N. Engl. J. Med. 372 (2015) 1441-1452.

[78] F. Sipos, T.M. Germann, B. Wichmann, O. Galamb, S. Spisák, T. Krenács, Z. Tulassay, B. Molnár, G. Múzes, MMP3 and CXCL1 are potent stromal protein markers of dysplasia-carcinoma transition in sporadic colorectal cancer, Eur. J. Cancer Prev. 23 (2014) 336-343.

[79] O. Galamb, B. Wichmann, F. Sipos, S. Spisák, T. Krenács, K. Tóth, K. Leiszter, A. Kalmár, Z. Tulassay, B. Molnár, Dysplasia-carcinoma transition specific transcripts in colonic biopsy samples, PLoS One 7 (2012) e48547.

[80] J. He, F. Zhang, L.W.R. Tay, S. Boroda, W. Nian, K.R. Levental, I. Levental, T.E. Harris, J.T. Chang, G. Du, Lipin-1 regulation of phospholipid synthesis maintains endoplasmic reticulum homeostasis and is critical for triple-negative breast cancer cell survival, FASEB J. 31 (2017) 2893-2904.

[81] L. Brohée, S. Demine, J. Willems, T. Arnould, A.C. Colige, C.F. Deroanne, Lipin-1 regulates cancer cell phenotype and is a potential target to potentiate rapamycin treatment, Oncotarget 6 (2015) 11264-11280. 
[82] X. Fan, Y. Weng, Y. Bai, Z. Wang, S. Wang, J. Zhu, F. Zhang, Lipin-1 determines lung cancer cell survival and chemotherapy sensitivity by regulation of endoplasmic reticulum homeostasis and autophagy, Cancer Med. 7 (2018) 2541-2554.

[83] H.K. Seitz, R. Bataller, H. Cortez-Pinto, B. Gao, A. Gual, C. Lackner, P. Mathurin, S. Mueller, G. Szabo, H. Tsukamoto, Alcoholic liver disease, Nat. Rev. Dis. Primers 4 (2018) 16.

[84] M. Hu, F. Wang, X. Li, C.Q. Rogers, X. Liang, B.N. Finck, M.S. Mitra, R. Zhang, D.A. Mitchell, M. You, Regulation of hepatic lipin-1 by ethanol: role of AMP-activated protein kinase/sterol regulatory element-binding protein 1 signaling in mice. Hepatology, 55 (2012) 437-446.

[85] J. Wang, C. Kim, A. Jogasuria, Y. Han, X. Hu, J. Wu, H. Shen, R. Chrast, B.N. Finck, M. You, Myeloid cell-specific lipin-1 deficiency stimulates endocrine adiponectin-FGF15 axis and ameliorates ethanol-induced liver injury in mice, Sci. Rep. 6 (2016) 34117.

[86] M. Hu, H. Yin, M.S. Mitra, X. Liang, J.M. Ajmo, K. Nadra, R. Chrast, B.N. Finck, M. You, Hepatic-specific lipin-1 deficiency exacerbates experimental alcohol-induced steatohepatitis in mice, Hepatology 58 (2013) 1953-1963.

[87] C. Michot, L. Hubert, M. Brivet, L. De Meirleir, V. Valayannopoulos, W. MüllerFelber, R. Venkateswaran, H. Ogier, I. Desguerre, C. Altuzarra, E. Thompson M. , Smitka, A. Huebner, M. Husson, R. Horvath, P. Chinnery, F.M. Vaz, A. Munnich, O. Elpeleg, A. Delahodde, Y. de Keyzer, P. de Lonlay, LPIN1 gene mutations: a major cause of severe rhabdomyolysis in early childhood, Hum. Mutat. 31 (2010) E1564-73.

[88] P. Zhang, M.A. Verity, K. Reue, Lipin-1 Regulates Autophagy Clearance and Intersects with Statin Drug Effects in Skeletal Muscle, Cell Metab. 20 (2014) 267-279.

[89] G.G. Schweitzer, S.L. Collier, Z. Chen, K.S. McCommis, S.K. Pittman, J. Yoshino, S.J. Matkovich, F.F. Hsu, R. Chrast, J.M. Eaton, T.E. Harris, C.C. Weihl, B.N. Finck, Loss of lipin 1-mediated phosphatidic acid phosphohydrolase activity in muscle leads to skeletal myopathy in mice, FASEB J, 33 (2019) 652-667.

[90] T. Rashid, I. Nemazanyy, C. Paolini, T. Tatsuta, P. Crespin, D. de Villeneuve, S. Brodesser, P. Benit, P. Rustin, M.A. Baraibar, O. Agbulut, A. Olivier, F. Protasi, T. Langer, R. Chrast, P. de Lonlay, H. de Foucauld, B. Blaauw, M. Pende, Lipin1 deficiency causes sarcoplasmic reticulum stress and chaperone-responsive myopathy, EMBO J. 38 (2019) e99576.

[91] J.Y. Lee, K.H. Sohn, S.H. Rhee, D. Hwang, Saturated fatty acids, but not unsaturated fatty acids, induce the expression of cyclooxygenase-2 mediated through Toll-like receptor 4, J. Biol. Chem. 276 (2001) 16683-16689.

[92] E. Erbay, V.R. Babaev, J.R. Mayers, L. Makowski, K.N. Charles, M.E. Snitow, S. Fazio, M.M. Wiest, S.M. Watkins, M.F. Linton, G.S. Hotamisligil, Reducing endoplasmic reticulum stress through a macrophage lipid chaperone alleviates atherosclerosis, Nat. Med. 15 (2009) 1383-1391. 
[93] G.I. Lancaster, K.G. Langley, N.A. Berglund, H.L. Kammoun, S. Reibe, E. Estevez, J. Weir, N.A. Mellett, G. Pernes, J.R.W. Conway, M.K.S. Lee, P. Timpson, A.J. Murphy, S.L. Masters, S. Gerondakis, N. Bartonicek, D.C. Kaczorowski, M.E. Dinger, P.J. Meikle, P.J. Bond, M.A. Febbraio, Evidence that TLR4 Is Not a Receptor for Saturated Fatty Acids but Mediates Lipid-Induced Inflammation by Reprogramming Macrophage Metabolism, Cell Metab. 27 (2018) 1096-1110.

[94] H.A. Majeed, M. Kalaawi, D. Mohanty, A.S. Teebi, M.F. Tunjekar, F. al-Gharbawy, S.A. Majeed, A.H. al-Gazzar, Congenital dyserythropoietic anemia and chronic recurrent multifocal osteomyelitis in three related children and the association with Sweet syndrome in two siblings, J. Pediatr. 115 (1989) 730-734.

[95] T. Herlin, B. Fiirgaard, M. Bjerre, G. Kerndrup, H. Hasle, X. Bing, P.J. Ferguson, Efficacy of anti-IL-1 treatment in Majeed syndrome, Ann. Rheum. Dis. 72 (2013) 410413.

[96] S.K. Vanaja, V.A. Rathinam, K.A. Fitzgerald, Mechanisms of inflammasome activation: recent advances and novel insights, Trends Cell Biol. 25 (2015) 308-15.

[97] H.M. Hoffman, J.L. Mueller, D.H. Broide, A.A. Wanderer, R.D. Kolodner, Mutation of a new gene encoding a putative pyrin-like protein causes familial cold autoinflammatory syndrome and Muckle-Wells syndrome, Nat Genet, 29 (2001) 301305.

[98] F. Martinon, K. Burns, J. Tschopp, The inflammasome: a molecular platform triggering activation of inflammatory caspases and processing of prolL-beta, Mol. Cell 10 (2002) 417-426.

[99] R. Muñoz-Planillo, P. Kuffa, G. Martínez-Colón, B.L. Smith, T.M. Rajendiran, G. Núñez, $\mathrm{K}^{+}$efflux is the common trigger of NLRP3 inflammasome activation by bacterial toxins and particulate matter, Immunity 38 (2013) 1142-1153.

[100] D. Perregaux, C.A. Gabel, Interleukin-1 $\beta$ maturation and release in response to ATP and nigericin. Evidence that potassium depletion mediated by these agents is a necessary and common feature of their activity, J. Biol. Chem. 269 (1994) 1519515203.

[101] K.A Hogquist, M.A. Nett, E.R. Unanue, D.D. Chaplin, Interleukin 1 is processed and released during apoptosis, Proc. Natl. Acad. Sci. U.S.A. 88 (1991): 8485-8489.

[102] P. Broz, V.M. Dixit, Inflammasomes: mechanism of assembly, regulation and signaling, Nat. Rev. Immunol. 16 (2016) 407-420.

[103] G. Lordén, I. Sanjuán-García, N. de Pablo, C. Meana, I. Alvarez-Miguel, M.T. Pérez-García, P. Pelegrín, J. Balsinde, M.A. Balboa, Lipin-2 regulates NLRP3 inflammasome by affecting P2X7 receptor Activation, J. Exp. Med. 214 (2017) 511-528.

[104] J.J. Baldassare, Y. Bi, C.J. Bellone, The role of p38 mitogen-activated protein kinase in IL-1 $\beta$ transcription, J. Immunol. 162 (1999) 5367-5373. 
[105] H. Hara, K. Tsuchiya, I. Kawamura, R. Fang, E. Hernandez-Cuellar, Y. Shen, J. Mizuguchi, E. Schweighoffer, V. Tybulewicz, M. Mitsuyama, Phosphorylation of the adaptor ASC acts as a molecular switch that controls the formation of speck-like aggregates and inflammasome activity, Nat. Immunol. 14 (2013) 1247-1255.

[106] Y. Gu, K. Kuida, H. Tsutsui, G. Ku, K. Hsiao, M.A. Fleming, N. Hayashi, K. Higashino, H. Okamura, K. Nakanishi, M. Kurimoto, T. Tanimoto, R.A. Flavell, V. Sato, M.W. Harding, D.J. Livingston, M.S. Su, Activation of interferon-gamma inducing factor mediated by interleukin-1beta converting enzyme, Science 275 (1997) 206-209.

[107] L.E. Robinson, M. Shridar, P. Smith, R.D. Murrell-Lagnado, Plasma membrane cholesterol as a regulator of human and rodent $\mathrm{P}^{2} \mathrm{X}_{7}$ receptor activation and sensitization, J. Biol. Chem. 289 (2014) 31983-31994.

[108] A.J. Cox, Y. Zhao, P.J. Ferguson, Chronic Recurrent Multifocal Osteomyelitis and Related Diseases-Update on Pathogenesis, Curr. Rheumatol. Rep. 19 (2017) 18. 